\title{
A EDUCAÇÃO LITERÁRIA SOB DUAS PERSPECTIVAS - objetivo comum
}

\author{
Lauro Roberto do Carmo Figueiral
}

\section{RESUMO}

O objetivo deste estudo foi estabelecer um paralelo entre o ensino da Literatura no Ensino Médio, no Brasil, e no Ensino Secundário, em Portugal. Confrontaram-se vários documentos legais que regem as diretrizes curriculares de ambos os países e chegou-se à conclusão de que as orientações nacionais não são efetivamente implementadas, ao contrário dos programas portugueses. Em Portugal, o Programa e Metas Curriculares de Português/2014 apresenta uma base comum curricular nacional em que discrimina conteúdos, competências e habilidades (descritores de desempenho) a serem executados pelo professor de modo que the ficam disponíveis apenas instrumentalizações metodológicas. Essas determinações definem a aplicação do referido Programa. No Brasil, os vários documentos definidores do ensino (Diretrizes e Parâmetros Curriculares Nacionais/Ensino Médio Linguagens) limitam-se a apresentar sugestões, reflexões e conteúdos, sem a deliberação curricular, proposição adversa da portuguesa. Ainda, a concepção de texto é diversa. Enquanto a orientação portuguesa opta pelo entendimento de texto complexo, elegendo o texto literário como o principal exemplo, na situação brasileira o texto literário subordina-se à perspectiva da Semiótica e da Linguística textual. Estas diferentes abordagens geram descompasso acerca do acesso direto à obra literária - enquanto no ensino português o aluno recebe uma lista de obras, no brasileiro, o aluno circunscreve-se a textos derivados de instruções e sugestões da historiografia literária, a resultar relativa efetividade da leitura. Concluiu-se também que o ensino do Português Iusitano prioriza a centralidade do texto literário, ao passo que o brasileiro destina a Literatura a compor uma subunidade dos conteúdos de Língua Portuguesa.

Palavras-chave: Currículo. Ensino. Literatura.

\section{TWO PERSPECTIVES ON LITERARY EDUCATION - common goal}

\begin{abstract}
The purpose of this study was to establish a comparison between the teaching of Literature in High School in Brazil and in Portugal. Several legal documents instructing the curriculum guidelines of both countries were confronted and it was concluded that, differently from those of Portugal, the Brazilian guidelines are not effectively

1 Doutor em Literatura (Universidade do Porto, Portugal). Professor do Programa de Letras/Instituto de Ciências da Educação, da Universidade Federal do Oeste do Pará. E-mail: laurocf@yahoo.com.br
\end{abstract}


implemented. In Portugal, the Portuguese/2014 Program and Curriculum Goals present a common national curricular basis discriminating contents, competences and abilities (performance descriptors) to be executed by the teacher so that only methodological instruments are available to him. These determinations define the application of the Program. In Brazil, the various documents defining teaching (Guidelines and National Curriculum Parameters/High School - Languages) are limited to presenting suggestions, reflections and contents, without curricular deliberation. This is different from what happens in the Portuguese educational system. The conception of text is also divergent. While the Portuguese orientation is toward understanding text as a complex phenomenon, choosing the literary text as the main example of that, in the Brazilian context the literary text is subordinated to the perspective of Semiotics and textual Linguistics. These different approaches generate a lack of access to literary work - while in Portuguese schools, students receive a list of works, in Brazilian schools, students are limited to texts derived from instructions and suggestions of the literary historiography resulting in relative effectiveness of reading. It was also concluded that the Lusitanian Portuguese teaching prioritizes the centrality of literary texts, while the Brazilian one confines Literature to compose a sub-unit of the contents of Portuguese Language.

Keywords: Curriculum. Teaching. Literature.

\section{LA EDUCACIÓN LITERARIA BAJO DOS PERSPECTIVAS - objetivo común}

\section{RESUMEN}

El objetivo de este estudio fue establecer un paralelo entre la enseñanza de la literatura en la escuela secundaria en Brasil y en la educación secundaria en Portugal. Se compararon varios documentos legales que rigen las directrices del plan de estudios en ambos países y se concluyó que las disposiciones nacionales no se aplican con eficacia, a diferencia de los programas portugueses En Portugal, el Programa y Metas Curriculares de Portugués/2014 cuenta con un plan de estudios nacional común basada en discriminar contenidos, destrezas y habilidades (descriptores de desempeño) a realizar por el profesor parael cual sólo están disponibles instrumentaciones metodológicas. Estos reglamentos definen la implementación del programa. En Brasil, los distintos documentos que definen la enseñanza (Diretrizes y Parámetros Curriculares Nacionales/EEducación Media Linguaje) se limitan a presentar reflexiones sugerencias, pensamientos y contenido, sin deliberación, proposición contraria de la portuguesa. Aún así la concepción del texto es diversa. Mientars la orientación portuguesa opta por el entendimento de textos complejos, eligiendo el texto literário como el principal ejemplo; en la situación brasileira el texto literário se subordina a la Semiótica e y de la Linguística textual. Estos diferentes abordajes generan falta de coincidencia sobre el acceso directo a la obra literaria -, mientras que en el caso portugués el estudiante recibe una lista de obras, en Brasil, el estudiante se limita a las instrucciones y consejos derivados de la historia literaria, el resultado de la eficacia relativa de la lectura. También se llegó a la conclusión de que la enseñanza portuguesa lusitano prioriza la centralidad del texto literario, y el caso brasilero se destina a la Literatura con la intención de componer una subunidad de contenido en lengua portuguesa.

Palabras clave: Plan de Estudios. Enseñanza. Literatura. 


\section{INTRODUÇÃO}

O escopo deste estudo é estabelecer um paralelo entre o ensino da Literatura no Brasil e em Portugal relativo aos três anos predecessores ao ensino superior ${ }^{2}$. Deste modo, limita-se a analisar o ensino da Literatura nos Cursos Científico-Humanísticos 3 , vocacionados para o prosseguimento de estudos de nível superior, na educação portuguesa, e ao Ensino Médio Regular, também destinado à consecução do nível superior, na brasileira.

A estruturação dos conteúdos dos Cursos Científico-Humanísticos, no ensino português, está consolidada em quatro áreas de conhecimento: Curso de Ciências e Tecnologias; Curso de Ciências Socioeconômicas; Curso de Línguas e Humanidades; Curso de Artes Visuais. A sistematização brasileira do Ensino Médio Regular, por sua vez, do mesmo modo, ancora-se em quatro áreas: Linguagens; Matemática; Ciências da Natureza; Ciências Humanas. O componente curricular Língua Portuguesa é transversal em todos esses segmentos, nos dois países.

Os documentos estruturadores brasileiros, Parâmetros Curriculares nacionais para o Ensino Médio, de 1999 e de 2002, bem como as Orientações Curriculares de 2006, para a área de Linguagens, Códigos e suas Tecnologias, cumprem a finalidade de sugerir, orientar e não prescrever as práticas de ensino e de aprendizagem do currículo escolar, a partir de uma base comum nacional. Sobretudo os PCNEM+/2002 4 e as OCNEM/2006 apresentam fundamentos teóricos, conceitos, conteúdos, habilidades e

2 A organização dos sistemas educativos de Portugal e do Brasil são diversos. Em Portugal, a estrutura escolar divide-se em dois níveis, Ensino Básico e Ensino Secundário. O primeiro é constituído por três ciclos: $1^{\circ} \mathrm{Ciclo}\left(1^{\circ}\right.$ ao $4^{\circ}$ ano $), 2^{\circ}$ Ciclo $\left(5^{\circ}\right.$ ao $6^{\circ}$ ano $)$ e $3^{\circ}$ ciclo $\left(7^{\circ}\right.$ ao $9^{\circ}$ ano). O segundo compreende três anos, $10^{\circ}, 11^{\circ}$ e $12^{\circ}$. No Brasil, são três fases escolares: Educação Infantil (Pré-Escola); Ensino Fundamental ( $1^{\circ}$ ao $9^{\circ}$ ano); Ensino Médio $\left(1^{\circ}\right.$ ao $3^{\circ}$ ano). Estes segmentos definem a Educação Básica, de acordo com a nomenclatura do MEC. Em ambos os países, há várias modalidades de escolaridade nos três últimos anos.

3 A oferta formativa para o Ensino Secundário Português compreende cinco modalidades: Cursos Científico-Humanísticos, Cursos com Planos Próprios, Cursos Artísticos Especializados, Cursos Profissionais, Ensino Secundário na Modalidade de Ensino Recorrente, Cursos Vocacionais.

4 Os Parâmetros Curriculares Nacionais+/Ensino Médio - Linguagens, Códigos e suas Tecnologias, de 2002, aprofundam as orientações sobre o ensino da Língua Portuguesa e da Literatura dos PCN de 1999. 
competências, que são deslindados e oferecidos ao profissional de Letras/Português como referências para a elaboração de projetos pedagógicos e planejamentos de planos individuais de aulas.

O estatuto de tais documentos condiciona a orientação curricular a propostas e sugestões de modo a permitir ampla flexibilização de uso do próprio conteúdo a aplicar e o emprego de metodologias sob a autonomia do professor. Os Parâmetros e as Orientações curriculares nacionais são as ferramentas maiores de apoio didático ${ }^{5}$ do professor brasileiro. Contudo, esses documentos orientadores privilegiam muitos conceitos e discorrem sobre diversas habilidades e competências sem sistematizar objetivamente um planejamento de implementação das disciplinas.

O Ministério da Educação e Cultura, no Brasil, está por homologar a versão última de uma Base Nacional Comum Curricularb para 0 Ensino Médio7. As diretivas para a construção dessa base nacional comum se fundamenta a partir da LDB/1996 e das Diretrizes Curriculares Nacionais para o Ensino Médio/1996. Neste sentido, embora não se possa apresentar aqui um debate a contemplar a BNCC/Ensino Médio/Língua Portuguesa, este estudo justifica-se e atualiza-se tendo em vista que todos os documentos gerados para o Ensino Médio foram produzidos consoantes esses dois documentos referenciados, LDB e DCNEM.

Portugal aprovou recentemente o novo Programa e Metas Curriculares de Português do Ensino Secundário. Entrou em vigor no ano letivo 2015/2016, com $\circ 10^{\circ}$ ano, e estender-se-á gradualmente aos dois níveis escolares subsequentes. A elaboração desse material de referência para o ensino da

5 O livro didático, nesse contexto, assenta em grande parte as atividades laborais do docente. Entretanto, o professor da rede pública de ensino, dependente de diretivas para executar suas atividades, experimenta um desalento ao se deparar com um livro didático de má qualidade, quando lhe destinam exemplares diferentes da lista tríplice sugerida pela equipe pedagógica da disciplina Língua Portuguesa, da escola, segundo testemunho de professores da rede pública do Ensino Médio.

6 A instituição BNCC é uma das exigências do Plano Nacional de Educação (2014-2024), em conformidade com marcos legais da Constituição/1988 e da Lei de Diretrizes e Bases da Educação/1996. A Base não é um currículo, mas uma referência de diretrizes norteadoras sob a qual cada rede de ensino ajustará ou construirá o próprio currículo.

7 Houve duas versões, até a presente data, em 25/10/2015 e 03/05/2016. Em 06 de abril de 2017, finalizou-se a Base comum para os ensinos Infantil e Fundamental. 
Língua Portuguesa, contrariamente às elaborações brasileiras, é mais objetivo, conciso e com uma didática prescritiva, logo, com maior possibilidade de execução. Esse documento, portanto, diferencia-se dos PCNEM/1999 e 2002, e das OCNEM/2006, por imprimir uma diretriz curricular a ser cumprida segundo um modelo geral que determina os conteúdos, os objetivos e os desempenhos. Da leitura do Programa e Metas, conclui-se que - professor recebe uma orientação didática determinante em face às elaborações brasileiras, que primam pela orientação geral sem a obrigatoriedade da execução de procedimentos didáticos prescritos. Os conteúdos e os descritores de desempenho, do Programa e Metas, ajustamse em propostas educativas, atribuindo ao professor a liberdade para operar a metodologia consoante os

[...] seus conhecimentos científicos, pedagógicos e didáticos [...] que considere mais adequados a uma aprendizagem bem sucedida dos conteúdos indicados em cada domínio, [...] tendo em conta especificidades científico-didáticas da disciplina, na sua articulação curricular horizontal e vertical ${ }^{8}$.

Na estrutura documental das duas referências educativas em pauta, a faculdade do professor sobre a operação metodológica é a única diretriz convergente. Neste sentido, o professor português se limita apenas a gerir didáticas de ensino, pois não tem a liberdade para organizar-se sob diversidades locais e regionais, previstas pelos documentos nacionais.

Entende-se que o modelo do Programa e Metas/2014, com as limitadas margens de opções oferecidas ao professor para a educação da língua materna e para a formação literária, corresponde ao contexto diferente em face do brasileiro. Portugal não apresenta quadros sociais, culturais, geográficos e econômicos comparáveis às diversidades atuais do Brasil.

O sistema educacional brasileiro vem operando ajustes a fim de

8 PORTUGAL. Ministério da Educação e Ciência. Programa e Metas Curriculares de Português - Ensino Secundário. Disponível em: <http://www.dge.mec.pt/sites/default/files/Secundario/Documentos/Documentos_Disciplina s_novo/progra_metas_curriculares_portugues_secundario.pdf $>$ Acesso em: 25 ago. 2015. p. 05. 
acompanhar as emergências múltiplas do país (sociais, geográficas, culturais, ideologias governamentais), com destaque para as orientações e mudanças na Lei de Diretrizes e Bases da Educação Nacional9. Debate-se, por exemplo, que os atuais $15 \%$ da carga horária curricular destinados à parte diversificada do currículo poderão dilatar-se para $20 \%$, na proposta da Base Nacional Comum Curricular. Pretende-se, desse modo, alcançar as heterogeneidades da territorialidade nacional. Uma matriz curricular sem as margens para contextualizações, como a portuguesa, deixaria de fora do ensino as raízes da diversidade e da multiculturalidade formativas do povo brasileiro ${ }^{10}$. Neste sentido, foram incorporadas, pelas Diretrizes Curriculares Nacionais para o Ensino Médio/2012 (DCNEM/Resolução n² 2/2012, de 30 de janeiro), subsídios para o ensino, em diferentes disciplinas, das etnias e culturas, que originaram a sociedade brasileira ${ }^{11}$.

9 Este texto foi construído sob a referência da LDB n 9.394, de 20 de dezembro de 1996. Entretanto, esta lei foi reformulada pela Lei $n^{\circ} 13.415$, de 16 de fevereiro de 2017, e nenhum documento orientador proveniente das recentes alterações foi divulgado até a presente data. Ainda, embora as reformulações acerca do componente curricular Língua Portuguesa ainda se encontrarem em fase de consolidação pela Base, este trabalho se fundamenta pelos documentos legais que enquadram essa Base.

10 A Lei $n^{\circ}$ 12.796, de 4 de abril de 2013 declara o seguinte desfecho: "Art. 26. Os currículos da educação infantil, do ensino fundamental e do ensino médio devem ter base nacional comum, a ser complementada, em cada sistema de ensino e em cada estabelecimento escolar, por uma parte diversificada, exigida pelas características regionais e locais da sociedade, da cultura, da economia e dos educandos." (BRASIL. MINISTÉRIO DA EDUCAÇÃO LEI $\mathbf{N}^{\circ} \mathbf{1 2 . 7 9 6}$, de $\mathbf{4}$ de abril de $\mathbf{2 0 1 3}$ - altera a Lei $n^{\circ}$ 9.934, de 20 de dezembro de 1996, que estabelece as diretrizes e bases da educação nacional. Disponível em: <http://www.planalto.gov.br/ccivil_03/_ato2011-2014/2013/lei/112796.htm>. Acesso em: 20/09/2015.)

11 a) O ensino da História do Brasil, que leva em conta as contribuições das diferentes culturas e etnias para a formação do povo brasileiro, especialmente das matrizes indígena, africana e europeia.

b) O estudo da História e Cultura Afro-Brasileira e Indígena, no âmbito de todo o currículo escolar, em especial nas áreas de Educação Artística e de Literatura e História brasileiras. BRASIL. Ministério da Educação. Resolução CNE/CEB RE $n^{\circ} 2$, de 30 de janeiro 2012. Define Diretrizes Curriculares Nacionais para $O$ Ensino Médio. Disponível em:<http://portal.mec.gov.br/index.php?option=com_docman\&view=download\&alias=9864 -rceb002-12\&category_slug=janeiro-2012-pdf\&ltemid=30192>. Acesso em: 20 nov. 2015. p. 03. Desse modo, os planejamentos das aulas da Língua Portuguesa passaram a considerar outras literaturas, além da Literatura Portuguesa. Seguindo estas normatizações, as literaturas de matrizes indígena e africana passam a constar nas atividades da Parte Diversificada do currículo, com maior incidência no Ensino Fundamental, e em cadeiras das licenciaturas em Letras.

Revista Exitus, Santarém/PA, Vol. 8, №2, p. 300 - 328, MAl/AGO 2018. 


\section{CAPÍTULO I PLANIFICAÇÃO DAS REFERÊNCIAS PARA A EDUCAÇÃO LITERÁRIA}

O Programa e Metas de Português do Ensino Secundário/2014 estrutura-se em cinco domínios articulados entre si ajustados a cada nível escolar. Os domínios da Oralidade, Leitura, Escrita, Educação Literária e Gramática são ensinados transversalmente, nos Cursos CientíficoHumanísticos, pela disciplina Língua Portuguesa, cujo objetivo primordial incide na competência eficaz do uso social da língua materna, ou seja, no exercício do trabalho, dos estudos, da cidadania e das manifestações cívicas. Esse Programa se estabelece a partir da valorização da Literatura Portuguesa, da centralidade do conceito de texto complexo e da noção de gênero textual, catalisadores para a formação intelectual, cultural e social do aluno secundarista. A defesa maior é a de uma perspectiva integradora do ensino da língua portuguesa concernente à valorização cultural, literária e linguística, tendo em vista os desempenhos descritos nas Metas desse Programa.

Os documentos de referência do sistema brasileiro, por sua vez, PCNEM+/2002 e OCNEM/200612, para 0 ensino da Língua Portuguesa/Literatura, organizam os conteúdos dessa disciplina articulados entre si e com outras disciplinas da área de Linguagens, sobretudo, considerando os conceitos de linguagem, texto e contexto. Pretende-se dar ao aluno uma instrução ampliada sobre diversas linguagens que se comunicam e prepará-lo para o reconhecimento e o uso delas nas diversas circunstâncias, dentro e fora da escola. Entende-se essa orientação interdisciplinar como uma idealização transcendente à formação do professor para o Ensino Médio, sendo que ele não recebe preparação interdisciplinar no curso superior. Esse descompasso estabelece um entrave nos sucessos da educação do Ensino Médio, envolvendo as diretrizes do MEC isoladas do seu destino, as falhas na implementação dessas orientações, a desorientação do professor sobre a sua formação e a

12 São referências documentais elaboradas como revisão e aprofundamento de todas as orientações anteriores, para o Ensino Médio, desde a LDB/1996 e a DCNEM/1996. 
consequente repetição de modelos de ensino.

Os PCNEM+/2002 apontam quatro domínios da disciplina Língua Portuguesa: Gramática, Literatura, Produção de Textos e Oralidade, e, por seu turno, as OCNEM/2006 apresentam como prioridade quatro habilidades: Escrita, Leitura, Fala e Escuta, tendo em mira o desenvolvimento da reflexão sistemática sobre a língua e a linguagem. Os Parâmetros+/2002 adotam o conceito de texto seguindo a compreensão de que todas as disciplinas da área de Linguagem, Códigos e suas Tecnologias são constituídas por textos para além da língua escrita ou falada:

Um quadro, uma letra de música em língua estrangeira, um número de dança, uma partida de determinado esporte, o hipertexto são tipos específicos de texto. O domínio deste conceito dependerá de abstrações feitas a partir de textos estruturados nas linguagens específicas e predominantes nas disciplinas da área (p. 32-33.).

A diretriz portuguesa também define o ensino da Língua Portuguesa pela adoção do texto. Entretanto, o Programa e Metas/2014 define o texto no sentido de texto complexo. A opção pela noção de texto complexo fundamenta-se em documentação e avaliação internacionais ${ }^{13}$, ao passo que a orientação brasileira espraia a sua abordagem pelo conceito de texto segundo as contribuições da Linguística e da Linguística Aplicada (OCNEM Linguagens, Códigos e suas Tecnologias, 2006). As propriedades qualitativas do texto complexo - relações, riqueza conceptual e formal, estrutura, estilo, vocabulário e intenção - percorrem a gradação crescente de texto "não

13 O excerto a seguir melhor explica: "O presente Programa repousa sobre a articulação destas questões com a defesa explícita, em documentos de referência recentemente produzidos em diferentes contextos de ensino da língua e da cultura maternas, da centralidade do texto complexo, cuja caracterização mais significativa é aqui realizada. Trata-se, por um lado, do conjunto de documentos que, no quadro da OCDE, se organizam em torno das orientações de referência para a educação do século XXI [...] e se articulam com Education Today: The OECD Perspective, publicação trienal sobre políticas educativas, e com as avaliações, igualmente trienais, conduzidas através do projeto PISA, que focam sempre, na avaliação das capacidades de leitura, a sua relação com o texto complexo; e, por outro, dos estudos que, nos Estados Unidos, deram origem às opções constantes dos Common Standards (o relatório ACT, 2006)." PORTUGAL. Ministério da Educação e Ciência, op. cit., p. 06. 
complicado", "desafiante" e "complexo"14. O Programa/2014 adota para o Ensino Secundário a aprendizagem da língua materna desta última qualidade e, entre as modalidades textuais (oral e escrito; literário e nãoliterário), a "valorização do literário como texto complexo por excelência" 15. Essa perspectiva sobre o entendimento da Literatura como expressão maior do texto complexo gera uma exigência de ensino e aprendizado a promover a leitura crítica e a fruição estética pela educação literária, e ao mesmo tempo da consistência da produção textual escrita.

A obra literária, nos documentos brasileiros, inversamente à valorização aqui exposta expressa nas diretrizes portuguesas, fica subordinada a uma insuficiente carga horária dentro da disciplina de Língua Portuguesa, mais ajustada a leituras metatextuais e a abordagens historiográficas. A ênfase é dada a estudos da linguagem e às atividades de produção, recepção e análise de textos escritos e orais, em diferentes práticas sociais de circulação de sentidos, assentadas na Linguística Textual, na Análise da Conversação e nas Teorias da Enunciação.

O texto complexo, no sentido da orientação portuguesa para o domínio da língua e da fruição estética, além de transmitir informações, também manifesta valores e perspectivas ${ }^{16}$. Neste contexto, o processo de ensino e de aprendizagem habilita o aluno a exercitar as competências de observação e de análise crítica da informação recebida dentro e fora da escola, e condu-lo à compreensão de que nem todas as formulações do pensamento são simples, e, por conseguinte, deve-se prosseguir à etapa posterior de descobertas:

É hoje possível argumentar que a complexidade textual se apresenta

\footnotetext{
14 BUESCU, Helena Carvalhão e SILVA, Maria Graciete. Conferência - Complexidade Textual. Disponível

$<$ http://www dge mecpt/sites/default/files/Formacao/es_conf_complexidade_textuat/hch: mgs.pdf.>. Acesso em: 30 set. 2015, p. 04.

15 Ibid., p. 01.

16 BUERLEIN, Mark, apud Programa e Metas de Português - Ensino Secundário. Disponível em: $<$ http://www.dge.mec.pt/sites/default/files/Secundario/Documentos/Documentos_Disciplina s_novo/progra_metas_curriculares_portugues_secundario.pdf $>$. Acesso em: 25 de ago. 2015, p. 07.
} 
como uma das variáveis decisivas na compreensão da leitura e, concomitantemente, na produção textual, em particular escrita. É ela que permite o desenvolvimento de capacidades de compreensão mais elaboradas e robustas, que naturalmente tenderão a refletir-se nas opções realizadas ao longo da vida, quer dentro da escola, quer fora dela ${ }^{17}$.

O Programa/2014 elabora para o Ensino Secundário a aprendizagem da leitura inferencial. O texto complexo corresponde aos desafios que 0 aluno desse nível de escolaridade deve enfrentar e a ele é apresentado o texto literário inserto nessa noção de complexidade. Os PNCEM+/2002, também, pressupõem que a aprendizagem básica da língua portuguesa, o correspondente aos textos "não complicado" e "desafiante", do Programa/2014, é um exercício de anterior escolaridade, sendo da competência do Ensino Médio

[...] oferecer aos estudantes oportunidades de uma compreensão mais aguçada dos mecanismos que regulam nossa língua, tendo como ponto de apoio alguns dos produtos mais caros às culturas letradas: textos escritos, especialmente os literários (PCNEM+Ensino Médio, 2002, p. 55).

Embora haja este discurso sobre a importância do texto literário para a competência linguística, é comum alunos testemunharem que concluíram a formação básica sem a leitura completa de um romance, por exemplo. Em contrapartida, a didática das leituras é outro no Programa/2014, a qual, a cada nível do Secundário, do $10^{\circ}$ ao $12^{\circ}$ ano, coordena leituras obrigatórias de obras poéticas e ficcionais, com as respectivas atividades decorrentes, além de um Projeto de Leitura, com a indicação de leituras integrais de obras literárias.

Por vieses diversos, a orientação brasileira, em parelha à portuguesa, está atenta à percepção das múltiplas possibilidades de expressão linguística do aluno e ao seu desenvolvimento de avaliação crítica, tendo em vista a capacitação para a leitura efetiva de textos diversos, a fim de que possa interpretá-los. Por sua vez, essa interpretação incide sobre a exposição

\footnotetext{
17 Ibid., p. 07.
} 
argumentativa lógica, por meio de texto oral ou escrito:

Para além da memorização mecânica de regras gramaticais ou das características de determinado movimento literário, o aluno deve ter meios para ampliar e articular conhecimentos e competências que possam ser mobilizadas nas inúmeras situações de uso da língua com que se depara, na família, entre amigos, na escola, no mundo do trabalho (PCNEM+ Ensino Médio, 2002, p. 55).

\section{CAPÍTULO II EDUCAÇÃO LITERÁRIA E LETRAMENTO LITERÁRIO}

As definições de texto complexo e literacia, e o reconhecimento do discurso literário como texto complexo por excelência, do Programa/2014, relacionam-se à descrição de letramento, nas OCNEM/2002. O uso treinado da linguagem conceptual em contextos diversos corresponde à literacia inclusiva, ou ao letramento, que é a capacidade de articulação dos conhecimentos do indivíduo na sociedade letrada. Na escola, o acesso à linguagem literária, para qual "convergem todas as hipóteses de realização da língua"18, contribui para uma formação global, pois o aluno lida com "um sentido denso, uma estrutura elaborada, um vocabulário sofisticado e intenções autorais subtis"19, conclui a equipe do citado Programa/2014.

Magda Soares (2004), no artigo "Letramento e alfabetização: as muitas facetas", informa sobre a coincidência da ocorrência imperativa, em um mesmo momento histórico, em sociedades distintas, "de reconhecer e nomear práticas sociais de leitura e de escrita mais avançadas e complexas que as práticas do ler e do escrever resultantes da aprendizagem do sistema de escrita." 20 . A autora registra que em meados dos anos de 1980, do último século, sobrevém o cultivo dos termos "letramento", no Brasil, "literacia", em Portugal, illetrisme, em França, para designar essa prática social de interação com a linguagem conceptual em distinção às denominações de "alfabetização" e alphabétisation. Literacia e letramento são traduções da palavra literacy, que, embora dicionarizada nos Estados

18 PORTUGAL. Ministério da Educação e Ciência, op. cit., p. 08.

19 BUERLEIN, op. cit., p. 07.

20 SOARES, M. Letramento e alfabetização: as muitas facetas. ISSN 1809-449X Rev. Bras. Educ. no.25 Rio de Janeiro Jan./Apr. 2004. Disponível em: < http://dx.doi.org/10.1590/S141324782004000100002>. Acesso em: 05 mai. 2016. p. 02. 
Unidos e na Inglaterra, desde o final do século XIX, foi por aquela década, de 1980, usada na área de educação e linguagem para descrever um entendimento diverso do que em língua inglesa se conhece como Reading instruction, begining literacy. Por fim, Soares comenta que, pelo final da década 1970, a Organização da Nações Unidas para a Educação, a Ciência e a Cultura (UNESCO) propõe o alargamento do conceito de literate para functionally literate, e sugere que as avaliações internacionais sobre o domínio das competências de leitura e de escrita meçam além da capacidade de apenas saber ler e escrever.

Esta breve digressão vincula o texto complexo à definição de literacia e letramento. Embora os documentos brasileiros não utilizarem o sintagma "complexidade textual", neles constam a exigência do Ensino Médio/Língua Portuguesa a lidar com textos de raciocínio elaborado, em que o aluno é educado a conhecer as múltiplas linguagens das práticas de letramento geradas pelas várias atividades sociais, e a experimentar, de modo crítico e lúdico, as situações de produção e leitura de textos:

O que se defende, portanto, é a absoluta necessidade de se avocar e levar adiante o desafio de criar condições para que os alunos construam sua autonomia nas sociedades contemporâneas tecnologicamente complexas e globalizadas - sem que, para isso, é claro, se vejam apartados da cultura e das demandas de suas comunidades. Isso significa dizer que a escola que se pretende efetivamente inclusiva e aberta à diversidade não pode ater-se ao letramento da letra, mas deve, isso sim, abrir-se para os múltiplos letramentos, que, envolvendo uma enorme variação de mídias, constroem-se de forma multissemiótica e híbrida - por exemplo, nos hipertextos na imprensa ou na internet, por vídeos e filmes, etc. Reitera-se que essa postura é condição para confrontar o aluno com práticas de linguagem que o levem a formar-se para o mundo do trabalho e para a cidadania com respeito pelas diferenças no modo de agir e de fazer sentido (OCNEM - Linguagens, Códigos e suas Tecnologias, 2002, p. 29).

A reflexão sobre o desenvolvimento de habilidades de uso da leitura e da escrita nas práticas sociais, nas OCNEM/2006, é extensivamente conduzida para a definição do letramento literário. A sociedade global, cada vez mais grafocêntrica, conduz o indivíduo para além da alfabetização. Aprender a ler e a escrever não significa aquisição da 
competência do uso da leitura e da escrita, logo, "Por extensão, podemos pensar em letramento literário como estado ou condição de quem não apenas é capaz de ler poesia ou drama, mas dele se apropriar efetivamente por meio da experiência estética, fruindo-o" (OCNEM - Linguagens, Códigos e suas Tecnologias, 2006, p. 55).

No Brasil, a alfabetização ampliou-se contrariamente à experiência da leitura do texto literário. Entre os fatores responsáveis por este descompasso, situam-se a reduzida carga horária destinada à leitura, a diluição da obra literária em variados discursos ou textos, a leitura de 'obras resumidas' ou de fragmentos de compilações, nos planos de aula do professor. Em que pesem os programas do MEC fomentarem a formação do leitor no ensino básico, ainda existe um fosso intransponível entre 0 aluno e o livro21. A equipe técnica que escreveu as OCNEM/2006 reconhece este problema na formação do aluno de todos os níveis de escolaridade, por isso advoga empenhos para habilitar o educando a experienciar a Literatura. A citação abaixo defende o contato do aluno com o texto e, entre as vantagens dessa experiência, salientam-se o reconhecimento das propriedades da linguagem literária; a liberdade para a exposição de pontos de vista subjetivos; o acesso a saberes que propiciem maior fruição; e a participação positiva do leitor:

Estamos entendendo por experiência literária o contato efetivo com o texto. Só assim será possível experimentar a sensação de estranhamento que a elaboração peculiar do texto literário, pelo uso incomum de linguagem, consegue produzir no leitor, o qual, por sua vez, estimulado, contribui com sua própria visão de mundo para a fruição estética. A experiência construída a partir dessa troca de significados possibilita, pois, a ampliação de horizontes, o questionamento do já dado, o encontro da sensibilidade, a reflexão,

${ }^{21}$ Faltam investigações para avaliar os planejamentos curriculares de leituras orientadas em sala de aula ou extraclasse, no Ensino Médio. A formação de leitores ainda é um dos problemas mais graves no domínio da Língua Portuguesa, apesar dos investimentos do MEC, que desenvolve, desde 2007, o Programa Nacional Biblioteca da Escola (PNBE), com a distribuição de acervos de obras literárias, de pesquisa e de referência. Esse investimento objetiva promover, entre estudantes e professores, a prática educativa da leitura literária, fonte de fruição, e ampliar conhecimentos por intermédio dos textos narrativo e poéticos. Ainda, como apoio para diminuir evasões e guarnecer suportes didáticos, o MEC, desde 2004, desenvolve o Programa Nacional do Livro Didático para o Ensino Médio (PNLEM). Alunos e professores da rede pública de todo o país passaram a receber gratuitamente, desde então, o livro didático de Língua Portuguesa/Literatura. 
enfim, um tipo de conhecimento diferente do científico, já que objetivamente não pode ser medido. O prazer estético é, então, compreendido aqui como conhecimento, participação, fruição. Desse modo, explica-se a razão do prazer estético mesmo diante de um texto que nos cause profunda tristeza ou horror [...] (OCNEM Linguagens, Códigos e suas Tecnologias, p. 55).

\section{CAPÍTULO III A CENTRALIDADE DO TEXTO LITERÁRIO}

O Programa/2014 reitera a importância do texto literário para o ensino da Língua Portuguesa, bem como seu papel para a aquisição do discurso conceptual. Além disso, o referido Programa considera a Literatura como um corpus essencial da memória de uma comunidade, constituindo um patrimônio a ser valorizado e estudado. Neste sentido, a presença do texto literário, no domínio da Educação Literária, suscita a aplicação do princípio da representatividade, em que cada obra literária é ensinada pelos seus valores estético, histórico-cultural e patrimonial, associados à Língua Portuguesa, nas suas extensões temporais presente e passado. O texto literário é, portanto, o resultado de um labor decorrente de uma aprendizagem discursiva secular, por isso para ele convergir um conjunto de fatores consolidados de relações lúdicas, conceituais, formais, estruturais, lexicais e objetividades demarcadoras de um texto complexo22. Compatível a estas conclusões, as OCNEM/2006 inscrevem a Literatura entre as muitas formulações discursivas, e compreendem que as propriedades do seu discurso decorrem de elaborações linguísticas inusitadas a explorar os limites das possibilidades da língua, sendo de todos o menos pragmático e transgressor. Neste sentido, o acesso ao texto literário garante ao estudante o exercício da liberdade (OCNEM - Linguagens, Códigos e suas Tecnologias, 2006, p. 49). Entretanto, essa compreensão das Orientações/2006 ficam isoladas no discurso do papel, porquanto o professor não analisa esses documentos por falta de efetiva implementação, nas escolas, das diretivas curriculares elaboradas pelo MEC.

No programa/2014, o texto literário é compreendido como representação e, por sua vez, nas OCNEM/2006, como produção simbólica

22 PORTUGAL. Ministério da Educação e Ciência, op. cit., p. 08. 
do domínio literário, portanto, ambos apregoam um pensamento comum sobre o papel da Literatura como instituto sociocultural. Os dois documentos pretendem implementar uma formação humanística e crítica do aluno, conduzindo-o a pensar sobre as realidades do mundo, sua história e identidade. Ainda entre as pretensões, as Orientações/2006 instruem sobre o cultivo de emoções e condições que favoreçam o reconhecimento da dimensão estética da obra, bem como a identificação do modelo discursivo da linguagem literária. A educação literária para o Ensino Médio, por conseguinte, deve ser diligenciada para a formação do gosto pela leitura e para o conhecimento da tradição literária local. Por fim, a didática literária deverá proporcionar instrumentos para que o aluno possa deslocar-se do leitor vítima ao leitor crítico23.

Por princípio, a educação implica também a comunhão democrática de saberes. Neste sentido, o Programa/2014 declara entre seus pressupostos cardinais "o direito de acesso a um capital cultural comum, que é função do sistema educativo, e o reconhecimento da diversidade dos usos da língua, numa ótica de valorização dos textos [...]"24. Restringindo-se apenas à educação pela Literatura, este pensamento é congruente às reflexões das OCNEM/2006. Os autores destas Orientações compreendem que pelas artes educa-se a sensibilidade; propicia-se a humanização do homem coisificado; e por elas transcende-se o imediato objetivo, o que favorece o prazer da liberdade, permitido pela fruição estética. Para estas Orientações, todo cidadão tem direito à apropriação artística. Neste sentido, fundamentam-se na LDB/1996: "Diríamos mesmo que têm mais direito aqueles que têm sido, por um mecanismo ideologicamente perverso, sistematicamente mais expropriados de tantos direitos, entre eles até o de pensar por si mesmos" (2006, p.53).

23 Umberto Eco distingue o leitor vítima - aquele sujeito a saber "o que" o texto conta, uma vítima do enunciado - do leitor crítico - interessado em "como" o texto narra e no modo de enunciação. O leitor crítico tem a habilidade de percorrer um arco mais abrangente de leituras, pois conhece as estratégias do enunciado, da enunciação e das representações da obra literária (ECO, Umberto apud OCNEM - Linguagens, Códigos e suas Tecnologias, 2006, p. 68-69).

24 PORTUGAL. Ministério da Educação e Ciência, op. cit., p. 05. 
As OCNEM/2006 demarcam a Literatura no sentido restrito, de arte construída pela palavra, de invenções poéticas, dramáticas e ficcionais da cultura letrada. Esta opção conceitual pretende assegurar "a democratização de uma esfera de produção cultural pouco ou menos acessível aos leitores, sobretudo da escola pública, fora do ambiente escolar" (2006, p. 60). Estas Orientações esclarecem que o cidadão menos instruído formalmente não transita pelas obras dos clássicos; seu ingresso não passa da literatura de massa, do folclore, de saberes espontâneos, da canção popular, que "são importantes e nobres, mas é grave considerá-las como suficientes para a grande maioria que, devido à pobreza e à ignorância, é impedida de chegar às obras eruditas" (CÂADIDO, 1995, p. 256-257). Estudiosos do ensino da Literatura em Portugal, os professores José Augusto Cardoso Bernardes e Rui Afonso Mateus, reforçam esta concepção de que o livro literário deve ingressar no currículo porque: "É também enquanto agente de uma educação integral e civicamente comprometida [...], que a literatura tem de reclamar o seu lugar na escola" (2013, p. 35).

O Programa/2014, no domínio Educação Literária, prioriza o acesso direto aos textos e às leituras fundamentadas, combinando reflexão e fruição. Do mesmo modo, releva o entendimento de que este domínio, assim como os domínios Oralidade, Leitura e Escrita, seja atitude de intervenção e socialização. Essa relação imediata com o livro é correspondente a um dos objetivos gerais do Programa/2014, direcionado para o ensino literário: "Ler, interpretar e apreciar textos literários, portugueses e estrangeiros, de diferentes épocas e géneros literários" 25 . Trata-se de uma proposta aberta para o contato com o livro escrito em língua portuguesa, segundo um programa estabelecido pelas orientações legais, seja de qualquer estilo, cultura ou época, e nacionalidade, desde que, no caso de livro estrangeiro, seja traduzido para o vernáculo. Esta estratégia de ensino é consolidada pelo Projeto de Leitura.

As OCNEM/2006, com a mesma perspectiva do Programa/2014,

25 Ibid., p. 11. 
propõem a centralidade da obra literária e o contato direto com ela, ou seja, a efetiva experiência literária. Estas Orientações relevam o contexto históricosocial e cultural, e as subjetividades que contribuíram para a construção do texto. Entretanto, para o ensino da Literatura, "O estudo das condições de produção estaria subordinado à pressão do discurso literário" (2006, p. 76-77). Nessas reflexões, os estudos sobre a história da Literatura seria um aprofundamento do estudo literário, reservando-se seu ensino para o último ano do Ensino Médio, ou para uma aprendizagem dos interessados em estudos especializados.

Os Conteúdos Programáticos do Programa e Metas/2014 de Português, para o Ensino Secundário, estão organizados em um quadro que descreve as atividades dos quatro domínios referidos, com seus respectivos conteúdos (temas) e tópicos de conteúdos prescritos a serem desenvolvidos. Em correspondência a esses conteúdos, foram elaborados, nas Metas Curriculares, por ano de escolaridade, objetivos e descritores de desempenho. No domínio da Educação Literária, observam-se três campos de descritores de desempenho, repetindo-se a cada série escolar: ler e interpretar textos literários; apreciar textos literários; situar obras literárias em função de grandes marcos históricos e culturais. Portanto, o professor português recebe, diversamente dos documentos brasileiros, que sugerem e fazem propostas de ensino, um manual comum pronto para execução, ficando sob sua responsabilidade apenas as metodologias a serem utilizadas.

Da poesia trovadoresca aos escritores da atualidade, autores são elencados com suas respectivas obras (em alguns casos, o professor pode optar por uma ou outra obra, mas sempre com restritas opções), às quais se segue um roteiro de atividades em sala de aula. A leitura das obras segue uma organização diacrônica e uma contextualização histórico-literária. Portanto, a reflexão sincrônica corresponde a um contexto necessário para o aluno situar-se no tempo histórico do texto a ler. O aluno secundarista português conhece seus clássicos e os muitos gêneros que produziram, 
enfim, a partir de uma grade nacional minuciosamente descrita a ser cumprida. Embora haja um ajuste por escola definido pelo Programa e Metas/2014, e o professor, por sua vez, tenha autonomia para organizar o plano de unidade de aula, este não tem liberdade pedagógica para selecionar quaisquer conteúdos.

A Educação Literária lusitana é complementada pelo Projeto de Leitura. Neste projeto, o aluno deve ler uma ou duas obras literárias de língua portuguesa - ou traduzidas para o português, entre as listadas - por ano de escolaridade. Ou seja, os livros estão catalogados distintamente, destinados a cada nível do Secundário, sem a repetição de autor entre os anos escolares. As leituras são realizadas paralelamente ao conteúdo programático, constituindo-se uma atividade extraclasse, posteriormente avaliada pelo professor. Este Projeto visa associar as leituras individuais aos conteúdos previstos em sala de aula, e favorecer a articulação entre os domínios da Oralidade e da Escrita, consolidada em avaliações.

O objetivo maior do Projeto de Leitura é a aprendizagem de outras culturas. $O$ aluno português, por meio da Literatura (traduzida), tem acesso a outros saberes, paisagens, culturas e linguagens. Entre os muitos autores estrangeiros, encontram-se os de nacionalidade alemã, austríaca, russa, africana, francesa, inglesa, marroquina, espanhola, italiana, etc. Autores clássicos, divisores de grandes épocas e escolas, e outros representantes de culturas antigas, constam entre as opções dos alunos.

Contrariamente, o aluno brasileiro não recebe programação de leituras extraclasse compatível com esse projeto de leitura português. É possível ocorrer orientações de leituras fora da sala de aula por planejamentos unilaterais de professores, ou em casos de engajamentos em projetos interinstitucionais de leitura, na escola. Acerca da abrangência da nacionalidade dos escritores, os documentos nacionais contemplam a leitura de obras de autores portugueses, africanos e indígenas. As Orientações/2006, por outro lado, apenas aconselham leituras de escritores estrangeiros. 
Nas escolas de Ensino Médio, a base comum é uma diretriz a ser respeitada, conforme a LDB/1996 e as DCNEM/1996, mas suas diretivas favorecem ampla flexibilização para o planejamento dos conteúdos curriculares. A futura Base Nacional também apresentará essa concepção, de que cada escola deverá se ajustar às premissas nela contidas. As Secretarias Estaduais de Educação recebem do MEC as diretrizes e os parâmetros curriculares, os quais são posteriormente entregues aos professores. A partir da aprovação da Base Nacional Comum Curricular/Ensino Médio, do mesmo modo, novas orientações chegarão ao professor por intermédio das secretarias estaduais de educação, tendo em conta as recentes mudanças na LDB/2017. Cada escola faz um planejamento anual de atividades, adaptando as diretrizes nacionais ao contexto local, e equipes de professores de disciplinas afins se reúnem para definir o plano de conteúdo das disciplinas. O professor tem autonomia para escolher conteúdos e aplicá-los, limitado pelas orientações legais.

As OCNEM/2006 atribuem ao professor a responsabilidade de mediador entre leitor e obra literária. As escolhas pessoais não devem dissociar-se do projeto pedagógico, mas é do professor a prerrogativa de escolher a leitura de obras integrais, bem como os gêneros literários. Contudo, essas Orientações reconhecem que o livro didático e os estilos de época cumprem sobremaneira a função de legitimar a leitura, e ambos, por anos, reproduzem os mesmos autores e textos, das diferentes fases da história da literatura brasileira, dirigindo os modos de ler a seleção. As OCNEM/2006 recomendam que as obras integrais devem ser acordadas entre os professores de Língua Portuguesa de cada escola, segundo uma organização sistemática para os três anos do Ensino Médio, com margem para escolha de autores não previstos.

Enquanto o Programa/2014 estabelece os autores e as leituras para o Ensino Secundário, as OCNEM/2002 lançam questionamentos sobre a escolha de um cânone literário. As indagações direcionam o processo de seleção das obras para leituras integrais, relativamente aos três anos do 
Ensino Médio, tendo em vista projeções de acréscimo de tempos e espaços escolares:

a) Quais são as obras e os autores que devem fazer parte do "acervo básico", aqui entendido como livros que serão lidos integralmente durante os três anos do ensino médio?

b) Que projetos desenvolver com vistas a possibilitar que os alunos leiam outros livros além das indicações do "acervo básico"? (OCNEM - Linguagens, Códigos e suas Tecnologias, p. 73).

Estas questões levantadas pelas OCNEM/2006 esclarecem a flexibilidade da construção do currículo para além do livro didático, fomentada pela natureza das áreas de conhecimento, estabelecidas pelas DCNEM/1996 e 2012. Os professores da rede pública de ensino trabalham em mais de uma escola e com muitas turmas, sobrando-lhes poucas horas para planejar projetos. As universidades, por meio de projetos de iniciação à docência, iniciação à pesquisa, e extensão, chegam até as escolas públicas, ampliando as expectativas de aprendizagem do aluno da escola pública. A intervenção universitária mobiliza alunos e professores a modificar paradigmas - por um lado, o graduando conhece o ambiente onde irá desempenhar suas funções docentes, por outro, professores e alunos das escolas passam a conhecer novas propostas de ensino e de aprendizagem, além de novos conhecimentos acadêmicos.

O vínculo entre a comunidade universitária e a comunidade escolar atende às necessidades preconizadas pelas OCNEM/2006. Exemplo de atividades conjuntas, reporta-se a um projeto de iniciação à docência, coordenado pelo autor deste trabalho, em duas escolas públicas do Ensino Médio, envolvendo quinze graduandos de Licenciatura em Letras - Língua Portuguesa, e três professores das escolas onde as atividades foram realizadas, entre os anos de 2012 e 2014. Esse projeto, com fomentos do PIBIB/CAPES-MEC, pautou-se pelo ensino da Literatura a partir da multiculturalidade, em que se optou por estudar escritores amazônicos. No primeiro semestre de 2015, outro projeto também financiado pelo MEC foi desenvolvido sobre leitura e produção de textos, seguindo o modelo anterior 
de ensino, com maior número de participantes - abarcando vinte alunos da Licenciatura, quatro professores e três escolas.

Ainda sobre a seleção de textos, as OCNEM/2006 recomendam prioridade à Literatura Brasileira, assim como o Programa/2014 privilegia a Literatura Portuguesa. Aquelas Orientações sugerem também leituras de autores fora da tradição, com a escolha de escritores contemporâneos e de outras nacionalidades. Porém, mais do que sugestão, no Projeto de Leitura, do Programa/2014, os livros sugeridos estão listados, à espera da escolha do aluno.

Embora Os PCNEM+/2002 e as OCNEM/2006 constituírem propostas e reflexões sobre os estudos literários, de modo mais assertivo, no primeiro documento, encontram-se quatro temas estruturadores para o ensino da Língua Portuguesa (e indiretamente ao ensino da Literatura), e os eixos temáticos geradores de conteúdos ${ }^{26}$. Mesmo assim, observam-se dificuldades para o professor organizar o seu ministério, pois em ambos documentos os conteúdos não estão sistematizados. Os grandes temas geradores de conteúdos, nos PCNEM+/2002, se desdobram em unidades temáticas amplas, sendo insuficientes para nortear a prática docente, de modo a exigir formação continuada do professor para preparar suas aulas.

Em contrapartida, a formulação do Programas e Metas/2014 é mais concisa e objetiva. Logo no início deste documento, verificam-se os domínios de sustentação do Programa de Português e os desdobramentos dos domínios fundamentados, que asseguram o ensino proposto. O domínio Educação Literária como um dos eixos norteadores dos conteúdos programáticos manifesta a importância cultural das Letras e ao mesmo

26 Os grandes temas sugeridos: 1. Usos da língua; 2. Diálogo entre textos: um exercício de leitura; 3. Ensino de gramática: algumas reflexões; 4. O texto como representação do imaginário e a construção do imaginário cultural. O conteúdo "Literatura" localiza-se no quarto grande tema, entre as Competências Gerais e as Competências Específicas. No primeiro caso, relacionado ao eixo da Representação e Comunicação, com a seguinte habilidade/competência, copiada dos PCNEM/1999: "recuperar, pelo estudo do texto literário, as formas instituídas de construção do imaginário coletivo, o patrimônio representativo da cultura e as classificações preservadas e divulgadas, no eixo temporal e espacial" (PCNEM+ Ensino Médio, 2002, p. 74). 
tempo a relevância da leitura literária no ensino da língua portuguesa, garantindo um aprendizado técnico, conceitual e prazeroso da língua.

\section{CONCLUSÕES}

Conclui-se, nesta investigação, que os cursos de licenciatura em Letras/Língua Portuguesa, no Brasil, ainda formam professores pouco aptos a enfrentar os desafios maiores da Educação Básica. As disciplinas desses cursos são geralmente organizadas em torno de três eixos: Língua Portuguesa/Linguística, Literatura/Teoria Literária e disciplinas de práticas pedagógicas. Estas são ministradas, ao final do curso, sob orientação de um professor da licenciatura em Letras e outro professor da escola onde a oficina docente ocorre, quando os formandos passam por dois estágios de prática de ensino. Nesse percurso, poucos estudos em torno da legislação sobre ensino são identificados na matriz curricular e no Projeto Político Pedagógico (PPC) do curso. E especificamente acerca das Diretrizes, dos Parâmetros e das Orientações curriculares ainda menos se estabelece debates entre formadores e formandos.

Compulsando a legislação sobre o ensino da Literatura, notadamente no Ensino Médio, identificou-se que a Lei de Diretrizes e Bases da Educação, as Resoluções que definem as Diretrizes Curriculares Nacionais e os Pareceres relativos a essas diretrizes são os fundamentos dos Parâmetros e das Orientações Curriculares para a Educação Básica, no Brasil. O conjunto desses documentos direciona a construção dos projetos pedagógicos e dos planos de aula individuais dos professores. Esta gama de documentos registra vinte e um anos de mobilização para acertar um caminho sistematizado em favor de uma escolarização básica de bom rendimento. Entretanto, a precariedade da formação docente (incluindo a formação continuada), a escassez da remuneração, o baixo prestígio profissional/social, a infraestrutura das escolas, a pobreza econômica da maioria dos brasileiros, e a incerteza na destinação das verbas para a 
educação em geral não têm permitindo avanços necessários no segmento educacional.

As orientações do MEC para a construção do currículo interdisciplinar e contextual consolidaram a divisão dos conhecimentos por áreas. Contudo, não se percebe, na área de Linguagens, uma preparação do professor adequada a essas exigências, apesar de os documentos propuserem possíveis atividades que articulem conteúdos afins, envolvendo disciplinas e áreas de conhecimento diversas. $O$ ensino interdisciplinar é ainda objeto de grandes debates no ensino superior. Sendo recorrente a aprovação desse modelo, no plano teórico, verifica-se que pouco ou nada concretamente se efetiva para o levar à prática tanto na formação dos licenciandos em Letras/Português quanto na execução curricular. As matrizes curriculares das faculdades continuam com as mesmas propostas delimitadas a cada curso. A Câmara e a Secretaria de Educação Básica, do Ministério da Educação, não se manifestam sobre essa abordagem curricular ausente nas faculdades formadoras de professores. Nem mesmo o documento orientador que realizou um estudo técnico sobre o processo de implementação das Diretrizes Curriculares Nacionais para o Ensino Médio, para a área de Linguagens, de 2015, reconheceu que o professor não tem condições de organizar suas aulas conforme as orientações que recebe, pois as faculdades de Letras não o preparam para exercer a sua atividade sob domínios interdisciplinares.

Esse estudo técnico (Projeto UNESCO/CNE Edital 7/2014, TOR 8/2014, de 23 de março, de 2015) constatou que os documentos norteadores responsáveis pela condução do ensino da Literatura ainda não consolidaram um modelo de ensino e de aprendizagem, no Brasil. Conclui-se que esse malogro decorre em razão de os dois Parâmetros e as Orientações curriculares nacionais apontarem direções gerais para a construção de projetos pedagógicos sem elencar os conteúdos dos componentes 
curriculares, os objetivos e as competências, de maneira sistematizada ${ }^{27}$. Desde o Parecer de 1998, que instrui as Diretrizes do mesmo ano, à segunda versão preliminar da Base Nacional Comum Curricular/2016, apenas nesta Base encontra-se uma proposta determinada do ensino literário, embora ainda the falte desmembrar os conteúdos dos objetivos e estabelecer delimitações das competências.

O Programa e Metas Curriculares de Português do Ensino Secundário/2014 apresenta uma estrutura de ensino coincidente em alguns fundamentos em face das orientações brasileiras, mas a lógica dos conteúdos afigura-se diferente. Entre os pontos convergentes, enfatiza-se a centralidade do texto literário. Contudo, embora a orientação seja o acesso direto ao texto literário, os documentos de referência brasileiros deixam sob a responsabilidade do professor a escolha das obras e o modo de conduzir a leitura, estabelecendo critérios e metodologias. O Programa/2014, pelo contrário, estabelece todas as leituras aos anos de escolaridade do Secundário e descreve a realização dos conteúdos e seus tópicos. Além destas orientações, o professor português ainda tem como auxílio para o planejamento das unidades de aula o livro didático. O professor brasileiro, por sua vez, se pauta pelos conhecimentos adquiridos no curso de sua formação, pelo livro didático, e pelas propostas genéricas dos PCNEM e das OCNEM - que se perdem ainda mais em meio a excesso de informações e reflexões sobre as linguagens. A Base nacional em fase de elaboração também não estrutura um conteúdo programático, deixando os parâmetros abertos da proposta intertextual que defende. Conclui-se que a implementação da disciplina Língua Portuguesa permanecerá carente de uma estrutura que descreva com minúcias os conteúdos, os objetivos, e as habilidades e competências, elementos estes bem demarcados pelas Metas Curriculares do Programa de Português/2014.

27 A falta da implementação das diretrizes gerais para o ensino é a agravada pelo seu conhecimento parcial ou desconhecimento absoluto. $O$ autor desta pesquisa realizou um inquérito junto a professores de Português/Ensino Médio, da rede pública, e verificou que alguns docentes apenas tiveram notícias desses documentos. 
O domínio Educação Literária, do Programa/2014, gera um descompasso entre Brasil e Portugal, relativo ao ensino da Literatura. Este programa apresenta a Educação Literária como um dos seus eixos, priorizando o texto literário, ao mesmo tempo em que relaciona a obra literária ao conceito de texto complexo e à definição de literacia. É evidente a compreensão do Programa/2014 sobre a necessidade do manuseio da literatura no contexto da aprendizagem da língua portuguesa para alcançar as finalidades do conhecimento e uso eficaz da língua materna e do acesso direto à obra literária. As OCNEM, por seu turno, descrevem os letramentos linguístico e literário, mas as leituras não são determinadas e a prioridade é a noção de texto segundo o ponto de vista de estudo delimitado pela área de Linguagens, na perspectiva multissemiótica - o texto de um quadro, de uma letra de música em língua estrangeira, de uma partida esportiva, etc. Em síntese, os responsáveis pela elaboração das referências para o ensino da Literatura, no Brasil, embora reconheçam a importância do letramento literário e da contribuição da linguagem literária na aprendizagem da língua vernácula, atestam, eles mesmos (a exemplo dos PCNEM+ e das OCNEM), que não foi priorizado o conteúdo da Literatura no âmbito do componente curricular Língua Portuguesa.

O novo Programa de Português/2014 finaliza a sua implementação no ano letivo 2017-2018, mas os seus fundamentos e a sua proposta de conteúdos relacionados aos descritores de desempenho confirmam um desenho cristalizado de experiências sobre o ensino da Literatura. A conformação desse Programa incentiva a formulação de documentos orientadores brasileiros mais objetivos e atinentes à relevância e à autoridade do texto literário para a formação do leitor. A expedição de documentos orientadores nesses vinte e um anos da LDB/1996, demonstram que propostas e sugestões, até então veiculados nos documentos de referência (Parâmetros e Orientações curriculares), são insuficientes para o planejamento de currículos. 
Este estudo não pode enunciar conclusões definitivas. O Programa/2014 implementou ainda duas fases correspondente ao $10^{\circ}$ ano e $11^{\circ}$ anos, nos exercícios escolares 2015/2016 e 2016/2017. Sua implementação definitiva ocorrerá no ano letivo 2017-2018. Na situação brasileira, a leitura dos documentos orientadores convergem para a Base Nacional Curricular/Ensino Médio, à espera de publicação. Mas, desde logo, pode-se afirmar que os documentos de referência anteriores à BNCC não conseguiram alcançar seus objetivos pela falta de melhores ajustes das orientações que chegaram ao professor. Ainda, não se pode deixar de observar que as propostas interdisciplinares permanecerão uma idealização enquanto a formação dos professores do Ensino Médio persistir dependente de um currículo acadêmico desprovida de instrução necessária para suas atividades docentes.

Quais recursos utilizar para construir o gosto pela leitura em um contexto avesso ao livro? Pesquisas atuais denunciam que mais da metade dos alunos de instituições de ensino superior, no Brasil, apresenta analfabetismo funcional, ou seja, são incapazes de exercitar habilidades de leitura, escrita e cálculo, imperativas para participação da vida social. A universalidade do ensino público e a proliferação de faculdades privadas de baixo custo propiciaram o ingresso de alunos com esse perfil, geralmente egressos da escola pública, a comprovar graves problemas da escolarização básica. De modo geral, os alunos ascendem ao curso superior sem o hábito de estudar, valendo-se de técnicas de memorização, conforme informações da DCNEM/1998. Atualmente, existem 13 milhões de jovens analfabetos funcionais acima de quinze anos, no Brasil, quantidade superior à população total de Portugal. A maioria desse contingente frequentou ou ainda frequenta a escola. Portanto, obter sucesso em conjuntura tão adversa constitui um desafio de grande complexidade. Construir um leitor assíduo e um escritor com domínios básicos sobre a Língua Portuguesa é o compromisso que se impõe sobre os responsáveis pelo ensino da língua e da literatura, no Brasil. 


\section{REFERÊNCIAS}

BERNARDES, J. C.; MATEUS, R. A. Literatura e Ensino do Português. Lisboa: Fundação Francisco Manuel dos Santos, 2013.

BRASIL. Ministério da Educação e Cultura. Lei de Diretrizes e Bases da Educação Nacional, Lei n 9.394, de 20 de dezembro de 1996. Estabelece as diretrizes e bases da educação nacional. Disponível em: <http://www.planalto.gov.br/ccivil_03/Leis/L9394.htm>. Acesso em 20 out. 2015.

BRASIL. Ministério da Educação e Cultura. Lei $\mathbf{n}^{\circ}$ 9.394/1996. Estabelece as Diretrizes e Bases da Educação Nacional. DOU 23.12.1996.

BRASIL. Ministério da Educação. Secretaria de Educação Média e Tecnológica. Parâmetros Curriculares Nacionais - Ensino Médio - Linguagens, Códigos e suas Tecnologias. Brasília: MEC/SEMTEC, 1999.

BRASIL. Secretaria de Educação Média e Tecnológica. PCN+ Ensino Médio: Orientações Educacionais complementares aos Parâmetros Curriculares Nacionais. Linguagens, códigos e suas tecnologias. Brasília: Ministério da Educação/Secretaria de Educação Média e Tecnológica, 2002.

BRASIL. Ministério da Educação e Desporto. Orientações Curriculares para o Ensino Médio - Linguagens, Códigos e suas Tecnologias. Brasília: MEC/Secretaria de Educação Básica, 2006.

BRASIL. Ministério da Educação. LEl n 12.796, de $\mathbf{4}$ de abril de 2013 - altera a Lei $n^{\circ} 9.934$, de 20 de dezembro de 1996, que estabelece as diretrizes e bases da educação nacional. Disponível em: <http://www.planalto.gov.br/ccivil_03/_ato2011-2014/2013/lei/l12796.htm>. Acesso em: 20 set. 2015.

BRASIL. Ministério da Educação e Cultura. Lei de Diretrizes e Bases da Educação Lei $n^{\circ}$ 12.796, de 4 de abril de 2013. Altera a Lei $n^{\circ} 9.394$, de 20 de dezembro de 1996, que estabelece as diretrizes e bases da educação profissional, para dispor sobre a formação dos profissionais da educação e dar outras providências. Disponível em: <http://www.planalto.gov.br/ccivil_03/_ato2011-2014/2013/lei/l12796.htm>. Acesso em: 15 jan. 2016.

BRASIL. Ministério da Educação e Cultura. Resolução CNE/CEB RE $n^{\circ} \mathbf{3}$, de 26 de junho de 1998. Institui as diretrizes curriculares para O Ensino Médio. Disponível em: http://portal.mec.gov.br/seb/arquivos/pdf/res0398.pdf > Acesso em: 20 ago. 2015.

BRASIL. Ministério da Educação (MEC), Secretaria de Educação Média e Tecnológica (Semtec). Parâmetros Curriculares Nacionais para o Ensino Médio. Brasília: MEC/Semtec, 1999. 
BRASIL. Parâmetros Curriculares Nacionais Ensino Médio/1999. Disponível em: <http://portal.mec.gov.br/seb/arquivos/pdf/14_24.pdf>. Acesso e 15 out. 2015.

BRASIL. Resolução CNE/CEB RE $n^{\circ}$ 4, de 13 de julho de 2010. Define Diretrizes Curriculares Nacionais Gerais para a Educação Básica. Disponível em: < http://portal.mec.gov.br/dmdocuments/rceb004_10.pdf>. Acesso em: 15 jan. 2015.

BRASIL. Parecer CNE/CEB $n^{\circ}$ 5, de 05 de maio de 2011. Disponível em: $<$ http://portal.mec.gov.br/index.php?option=com_docman\&view=download \&alias=8016-pceb005-11 \&category_slug=maio-2011-pdf\&ltemid=30192>.

Acesso em: 20 set. 2015.

BRASIL. Resolução CNE/CEB RE $\mathbf{n}^{\circ}$ 2, de 30 de janeiro 2012. Define Diretrizes Curriculares Nacionais para $\mathrm{E}$ Ensino Médio. Disponível em: < http://portal.mec.gov.br/index.php?option=com_docman\&view=download \&alias=9864-rceb002-12\&category_slug=janeiro-2012-pdf\&ltemid=30192> . Acesso em: 20 nov. 2015.

BRASIL. Projeto UNESCO Edital 7/2014, TOR 8/2014, Diretrizes Curriculares Nacionais para o Ensino Médio, no âmbito do Projeto UNESCO/CNE 914BRZ 1144.3.

Disponível

em

<https://www.google.com.br/url? sa=t\&source=web\&rct=j\&url=http://portal.m ec.gov.br/docman/> Acesso em: 20 fev. 2016.> Acesso em: 04 jan. 2016.

BRASIL. Ministério da Educação. Base Nacional Comum Curricular $-1^{a}$ Versão Preliminar (25/10/2015). Disponível em: <http://basenacionalcomum.mec.gov.br/documentos/BNCC-

APRESENTACAO.pdf >. Acesso em: 30 out. 2015.

BRASIL. Ministério da Educação. Base Nacional Comum Curricular - $2^{a}$ Versão Preliminar Revista. Disponível em: $<$ http://basenacionalcomum.mec.gov.br/documentos/bncc-

2 versao.revista.pdf>. Acesso em: 05 jun. 2016. p. 494.

CÂNDIDO, A. O direito à literatura. In: Vários escritos, 3. ed. São Paulo: Duas Cidades, 1995.

CONSELHO NACIONAL DE EDUCAÇÃO E DESPORTO. Diretrizes curriculares Nacionais - Educação Básica, Braślia, 2001.

COSTA-HÜBES, C. Relatórios analíticos das contribuições, pareceres dos leitores críticos e diretrizes da revisão do documento preliminar. In: BRASIL. Ministério da Educação. Disponível em: <http://basenacionalcomum.mec.gov.br/\#/site/relatorios-analiticos>. Acesso em: 05 jun. 2016.

PORTUGAL. Ministério da Educação e Ciência. Programa e Metas Curriculares de Português - Ensino Secundário. Disponível em: http://www.dge.mec.pt/sites/default/files/Secundario/Documentos/Docume ntos_Disciplinas_novo/progra_metas_curriculares_portugues_secundario.pdf > Acesso em: 25 ago. 2015. p. 05. 
SOARES, M. Letramento e alfabetização: as muitas facetas. ISSN 1809-449X Rev. Bras. Educ. no.25 Rio de Janeiro Jan./Apr. 2004. Disponível em: <http://dx.doi.org/10.1590/S1413-24782004000100002>. Acesso em: 05 mai. 2016.

Recebido em: Outubro de 2017 Aprovado em: Janeiro de 2018 